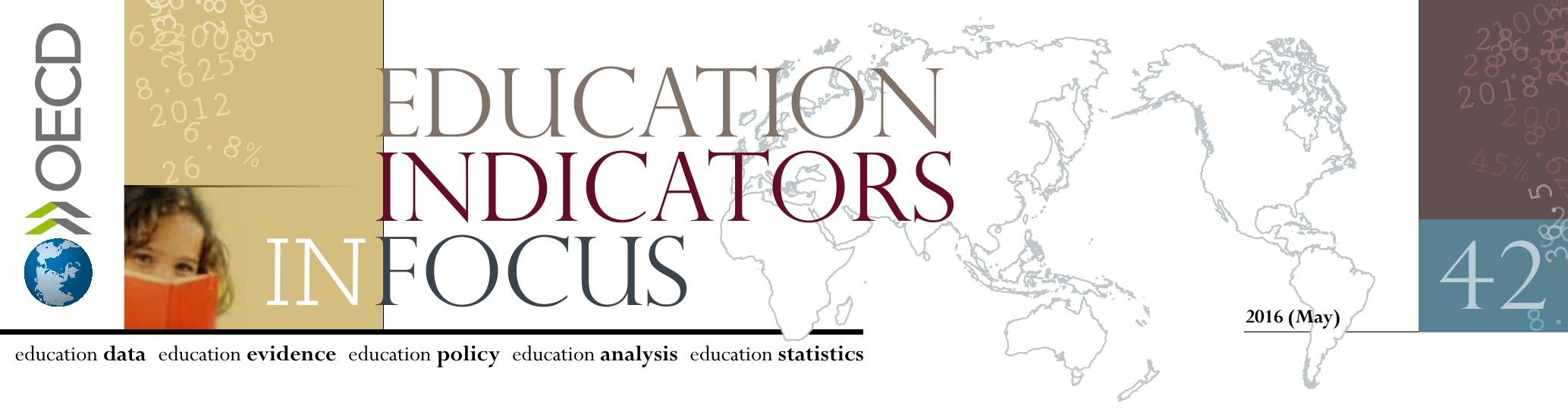

\title{
What are the benefits from early childhood education?
}

- Early childhood education and care programmes (ECEC) have become more accessible in recent years, with high enrolment rates in both early childhood educational development and preprimary education.

- The educational results of students at the age of 15 may be partially explained by attendance at pre-primary education, which sharply decreases the likelihood of low performance in the Programme for International Student Assessment (PISA).

- Pre-primary education can play a strong role in promoting equality at an early age, particularly by targeting disadvantaged groups such as first- and second-generation immigrants.

- Assuring and monitoring the quality of programmes is key to guaranteeing that early childhood education and care has a positive impact on both equity and performance in education.

Within the OECD, enrolment in early childhood education is very high.

The International Standard Classification of Education (ISCED) divides early childhood education programmes (ECE) into two groups according to their level of complexity and the age of the children enrolled: early childhood educational development (ISCED 0.1) and pre-primary education (ISCED 0.2). Both have an education component, although they have different focuses. Early childhood educational development programmes are usually designed for children under three years old and focus on communication skills, especially language acquisition, as well as initial motor activities and socio-emotional development.

Pre-primary education is structured as an introductory programme to prepare students aged between three and six years old for compulsory education; they provide children with basic alphabetical and mathematical concepts and initial logical and reasoning skills (UNESCO, 2012). Programmes such as childcare are not included in ECE and not captured by the Education at a Glance data, although their impact is discussed in other publications and research papers. Childcare programmes are often analysed in combination with ECE programmes under the broader early childhood education and care (ECEC) category. Enrolment in early childhood education and care increased sharply in the 1970s and 1980s, coinciding with growing female participation in the labour market. Its original main objective was to provide care for young children, thus allowing parents to work and facilitating a balance between work and family responsibilities. In recent years, however, the focus of those programmes has shifted from parents' needs to children's development (OECD, 2011). This has coincided with greater government involvement aimed at guaranteeing that ECEC is equipping children with better skills and the competencies needed to start compulsory education, and addressing socio-economic inequality early on in children's development.

Figure 1 shows that in 2013 many OECD countries had close to universal coverage of early childhood education. On average, three-quarters of children aged 3 were enrolled in either ISCED 01 or ISCED 02, the latter being considerably more common in all countries except Australia, Brazil and Colombia. Among 4-year-olds, 20 of the 31 OECD countries with data available had enrolment rates of over $90 \%$. However, there is still strong variation across OECD countries, and in Ireland, Mexico, Switzerland, Turkey and the United States less than half of all 3-year-olds were enrolled in an ECE programme.

\section{ECEC helps children boost performance and develop social and emotional skills.}

The success of ECEC in preparing students for higher levels of education has shifted the focus of those programmes from parents' to children's interests (OECD, 2011). Skills development at ECEC level is of particular importance as children are more sensitive at this stage than in later levels of education, meaning that they are more able to acquire fundamental skills that will be used throughout their educational and professional lives (OECD, 2015a).

The impact of early education in fostering a greater ability to learn in later stages is well summarised by Heckman's concept "Skills beget skills" (Heckman, 2008). The idea behind this expression is that skills achieved in early stages of education contribute to the development of other skills required in later educational levels and professional life. Moreover, evidence from the Effective Provision of Pre-School Education (EPPE) project confirms the particular role of early childhood education 
in the performance of disadvantaged children before they enter primary school. Furthermore, the project shows that all children benefit from preschool, which enhances their intellectual development and improves their independence, concentration and sociability (Siraj-Blatchford, 2010).

Figure 2 illustrates the lasting impact of ECE, linking better performance in the Programme for International Student Assessment (PISA) at the age of 15 with previous participation in early childhood education. For most countries, there are fewer low performers in maths among children who attended more than one year of pre-primary education than among those who did not attend any pre-primary education at all (OECD, 2016a). The difference continues to be significant even when controlling for socio-economic status, gender, immigrant background, language spoken at home, family structure, location of student's school (rural area, town or city), grade repetition and programme orientation (vocational or general).

High-quality early childhood education also provides children with an opportunity to develop social and emotional skills such as openness to new experiences, conscientiousness, extraversion, agreeableness and neuroticism, all of which tend to foster individual and societal progress. Skills for Social Progress: The Power of Social and Emotional Skills (OECD, 2015a) gives some examples of the link between social and emotional skills and educational performance, employment and health. In fact, the early development of social and emotional skills is a better predictor of college completion in the United States than that of cognitive skills. In Norway, adults in their late twenties with well-developed skills such as extraversion and self-confidence are considerably less likely to be depressed. In general, this set of skills is also a strong predictor of success later in life, when adults join the labour market (OECD, 2015a).

\section{Fighting inequality in outcomes requires an early start.}

In an increasingly unequal world - in the last decade, the income of the richest $10 \%$ increased by one-tenth but stagnated for the other 90\% and even decreased for the bottom 10\% (OECD, 2016b) - ECEC is central to reducing inequality from the start. Early enrolment in school is one way governments can help children from disadvantaged families catch up with their peers before starting primary education. Differences in learning patterns need to be assessed and addressed at a young age in order to stop inequality increasing at higher educational levels and later on in the labour market.

Targeting immigrant students in the process.

Current trends point to a more integrated world, with increasing numbers of immigrants, who often belong to lower income groups in host countries (OECD, 2015c). On average, across the OECD, the share of the foreign-born population has increased from $6 \%$ to over $9 \%$ over the last 2 decades. Increased mobility leading to greater diversity requires particular efforts towards integration, especially in initial stages of education. 
Figure 2. Pre-primary education and performance at the age of 15 (2012)

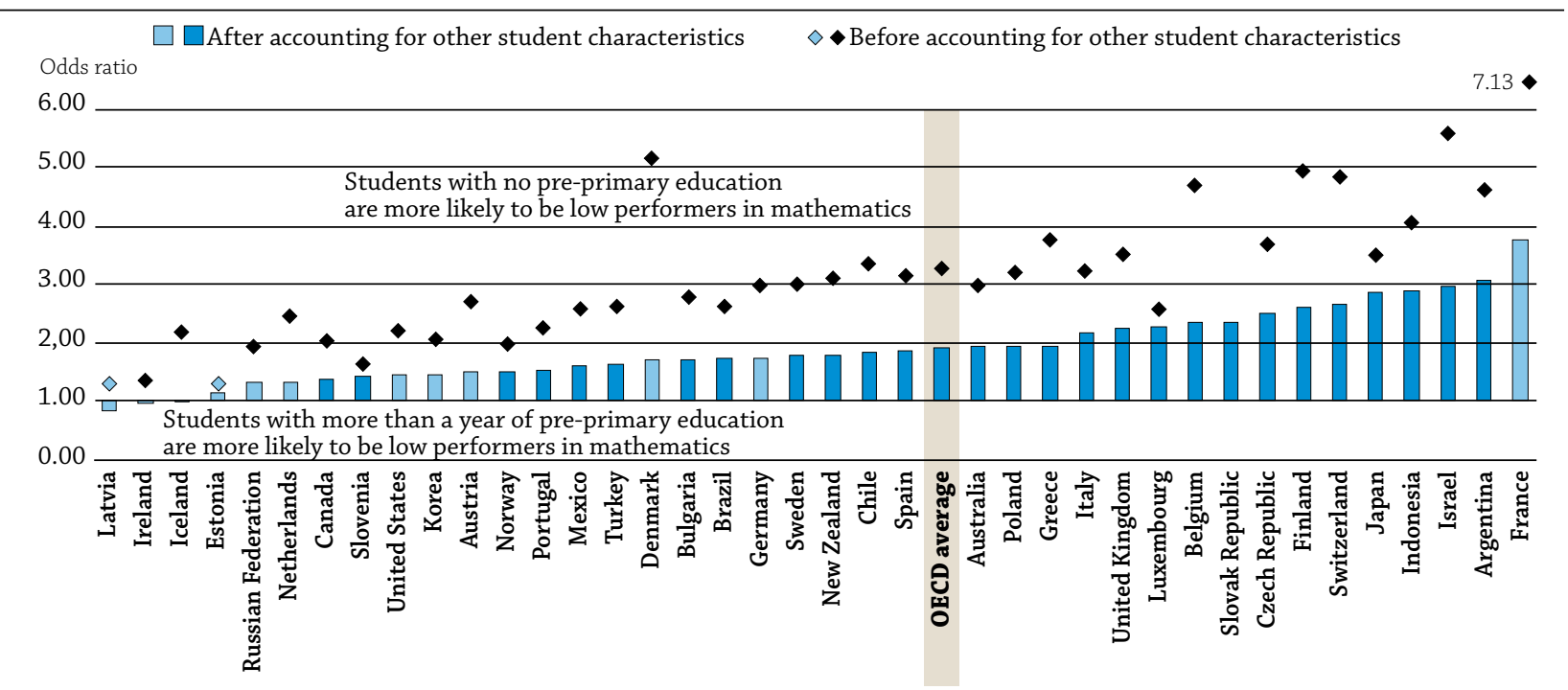

Notes: Statistically significant coefficients are marked in a darker tone

Other student characteristics include: socio-economic status, gender, immigrant background, language spoken at home, family structure, location of student's school (rural area, town or city), grade repetition and programme orientation (vocational or general).

Countries and economies are ranked in ascending order of the odds ratio of students who had no pre-primary education (Panel A) or who had a year or less of pre-primary education (Panel B) performing below the proficiency baseline Level $2 \mathrm{in}$ mathematics compared to students with more than a year of pre-primary education, after accounting for other student characteristics.

Source: OECD (2016a), Low-Performing Students: Why They Fall Behind and How to Help Them Succeed, PISA, OECD Publishing, Paris, http://dx.doi. org/10.1787/9789264250246-en.

Integrating young immigrant children into their new communities is of key importance in the long run and their flexibility and the rapidity with which they are capable of learning a local language makes the task easier. One of the ways in which education systems can help is by encouraging their enrolment in pre-primary education programmes. In most countries, participation in those programmes among immigrant children is considerably lower than that among those without an immigrant background (OECD, 2015c).

Indeed, as Figure 3 shows, across OECD countries, immigrant students who reported that they had attended pre-primary education programmes scored 49 points higher in the PISA reading assessment than immigrant students who reported that they had not. This difference in the PISA reading score corresponds to roughly one more year of education. However, part of this difference is explained by socio-economic factors, given that in many countries local and migrant children from more privileged households are more likely to attend pre-primary school.

\section{Focus on high-quality education.}

Enrolment in early childhood education is not enough on its own; the quality of programmes must also be observed and monitored and the results used to improve them. Some quality indicators include the child-staff ratio, the duration of programmes and public spending per child. However, beyond gathering descriptive statistics, monitoring the quality and impact of pre-primary education systems is not a well-developed practice across OECD countries. Monitoring processes tend to focus more on compliance with regulations than on the quality of service delivery or assessing how well children's needs are being identified and met (OECD, 2015b).

A few OECD countries have developed systems to benchmark and monitor children's progress, including children from different socio-economic and ethnic groups. Some countries use school entry tests to focus on child development and to provide information on how young children are progressing. Australia, for example, uses a national adaptation of the Early Development Instrument (EDI). The EDI, originally developed in Ontario, Canada, is a measure of children's development as they enter school. Teachers complete a checklist measuring children's physical health and well-being, social competence, emotional maturity, language, cognitive and communication skills, and general knowledge. The results are aggregated to the group level (school, neighbourhood, city) to provide a population-based measure of children's development (OECD, 2015a). Despite being a useful measurement tool, EDI still has limitations as it uses information reported by teachers, rather than independent moderators. 


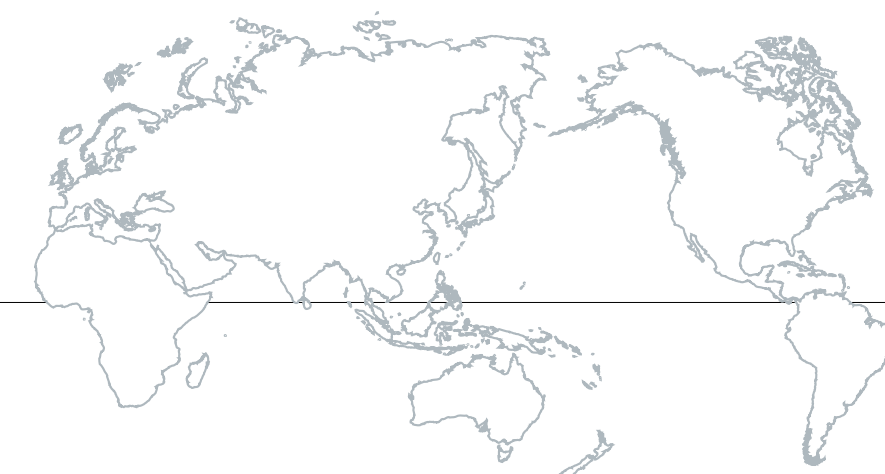

Figure 3. Pre-primary education and reading performance of immigrant students (2012)

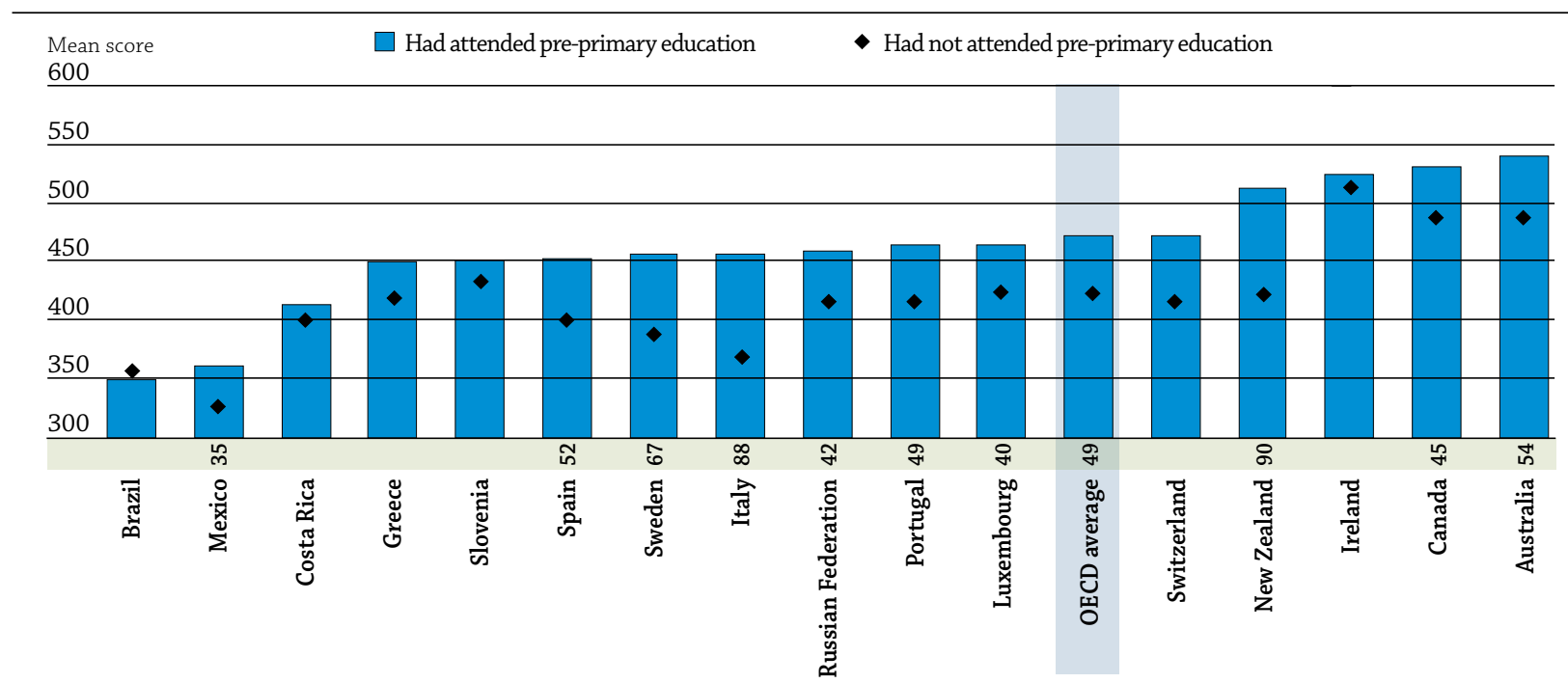

Note: Statistically significant score-point differences in reading performance between immigrant students who had attended pre-primary education and those who had not are shown next to the country/economy name.

Countries and economies are ranked in ascending order of the reading score of immigrant students who had attended pre-primary education.

Source: OECD (2015c), Immigrant Students at School: Easing the Journey towards Integration, OECD Reviews of Migrant Education, OECD Publishing, Paris, http://dx.doi.org/10.1787/9789264249509-en.

The bottom line: Evidence shows that early childhood education leads to the development of cognitive, social and emotional skills at a young age as well as to better school performance later on. It also creates conditions for lifelong learning and better future professional achievement. Furthermore, efforts to ensure quality early childhood education programmes may help to decrease the level of inequality between students and reduce the impact of socioeconomic differences in education.

\section{For more information}

Heckman, J. (2008), “Schools, skills, and synapses”, Economic Inquiry, Vol. 46/3, pp. 289-324.

OECD (2016a), Low-Performing Students: Why They Fall Behind and How to Help Them Succeed, PISA, OECD Publishing, Paris, http://dx.doi. org/10.1787/9789264250246-en.

OECD (2016b), Trends Shaping Education 2016, OECD Publishing, Paris, http://dx.doi.org/10.1787/trends edu-2016-en.

OECD (2015a), Skills for Social Progress: The Power of Social and Emotional Skills, OECD Skills Studies, OECD Publishing, Paris, http://dx.doi. org/10.1787/9789264226159-en.

OECD (2015b), Starting Strong IV: Monitoring Quality in Early Childhood Education and Care, OECD Publishing, Paris, http://dx.doi. org/10.1787/9789264233515-en.

OECD (2015c), Immigrant Students at School: Easing the Journey towards Integration, OECD Reviews of Migrant Education, OECD Publishing, Paris, http://dx.doi.org/10.1787/9789264249509-en.

OECD (2015d), Education at a Glance: OECD Indicators, OECD Publishing, Paris, http://dx.doi.org/10.1787/eag-2015-en.

OECD (2011), Doing Better for Families, OECD Publishing, Paris, http://dx.doi.org/10.1787/9789264098732-en.

Siraj-Blatchford, I. (2010), “The EPPE settings in the context of English pre-schools”, in Sylva et al. (eds.), Early Childhood Matters: Evidence from the Effective Pre-school and Primary Education Project, Routledge, London/New York.

UNESCO (2012), International Standard Classification of Education: ISCED 2011, United Nations Educational, Scientific and Cultural Organisation.

\section{Contact}

Diogo Amaro de Paula (diogo.amaro@oecd.org)

\section{Visit}

www.oecd.org/education/education-at-a-glance-19991487.htm Education Indicators in Focus (previous issues)

PISA in Focus

Teaching in Focus

\section{Next topic}

Sub-national variations in educational attainment and labour market outcomes.

Photo credit: @ Ghislain \& Marie David de Lossy/Cultura/Getty Images This paper is published under the responsibility of the Secretary-General of the OECD. The opinions expressed and arguments employed herein do not necessarily reflect the official

This document and any map included herein are without prejudice to the status of or sovereignty over any territory, to the delimitation of international frontiers and boundaries and to the name of any territory, city or area.

The statistical data for Israel are supplied by and under the responsibility of the relevant Israeli authorities. The use of such data by the OECD is without prejudice to the status of the Golan Heights, East Jerusalem and Israeli settlements in the West Bank under the terms of international law. 